Rabaska

Revue d'ethnologie de l'Amérique française

\title{
Le Groupe de recherche européen sur les narrations orales (Ergon/Greno)
}

\section{Greno}

Volume 6, 2008

URI : https://id.erudit.org/iderudit/019991ar

DOI : https://doi.org/10.7202/019991ar

Aller au sommaire du numéro

Éditeur(s)

Société québécoise d'ethnologie

ISSN

1703-7433 (imprimé)

1916-7350 (numérique)

Découvrir la revue

Citer ce document

Greno (2008). Le Groupe de recherche européen sur les narrations orales

(Ergon/Greno). Rabaska, 6, 121-122. https://doi.org/10.7202/019991ar d'utilisation que vous pouvez consulter en ligne.

https://apropos.erudit.org/fr/usagers/politique-dutilisation/ 


\section{Le Groupe de recherche européen sur les narrations orales (ERGON/GRENo)}

GRENO

\section{De Toulouse à Athènes}

Faisant suite aux premières Journées d'étude internationales sur le classement et l'analyse des contes populaires, organisées par Josiane Bru et Dominique Blanc à Toulouse, en novembre 2003 dans le cadre du GrEMOc et du Centre d'anthropologie, une quatrième rencontre s'est tenue à Athènes les 8,9 et 10 mai 2008. Elle était organisée, à l'initiative d'Anna Angelopoulos, responsable du Catalogue des contes populaires grecs dont un nouveau volume vient de paraître, par Georges Evgenikos, président du Centre pour l'étude et la diffusion des mythes et des contes (www.e-mythos.eu), et Nikoleta Xiprilidou.

La plupart des spécialistes européens présents à Toulouse en 2003, auxquels s'étaient joints des chercheuses grecques associées à la rédaction du Catalogue grec, ont travaillé durant deux jours en table ronde sur la question des Contes-nouvelles, une catégorie de contes de transmission orale dont la spécificité est difficile à cerner. Ils ont ensuite donné, à l'intention d'un auditoire de chercheurs et d'étudiants de l'Université d'Athènes qui ont activement participé aux discussions, une série de conférences publiques sur les contes populaires européens.

Entre la rencontre toulousaine fondatrice et les journées d'Athènes, deux autres réunions se sont tenues qui ont contribué à préciser les interrogations communes sur les répertoires narratifs recueillis : à Pau, en mars 2006, à l'initiative de Patricia Heiniger-Casteret, sur le thème «Tradition orale et récit facétieux ", où ont été confrontés non seulement des récits mais aussi des formes de l'art narratif oral contemporain, avec la participation de conteurs ruraux dont la création personnelle s'appuie sur les récits transmis directement mais aussi sur les adaptations littéraires d'écrivains régionaux ; à Palma de Mallorca, en novembre 2006, à l'initiative des collègues des universités de Tarragona et de Majorque, où la question de «La classificació de les rondalles : tipus, gèneres, arxius » a plus précisément porté sur le traitement des récits n'entrant pas, jusqu'ici, dans la classification internationale et susceptibles de disparaître du champ de la recherche faute de critères permettant de les repérer et de les classer. 
Ces contes sont intégrés, au même titre que les versions de contes-types connus, par les chercheurs catalans dans une base de données ouverte récemment à la consultation publique sur le site RondCat (Rondales catalanes : www.sre.urv.cat/rondcat). Cette base de données multilingue (en catalan, français, anglais et espagnol) permet de rechercher une information bibliographique, typologique et de contenu sur les contes folkloriques catalans de tradition orale.

\section{Le groupe de travail}

La convergence des questions qui se posent à eux et le climat d'écoute mutuelle qui s'est établi entre eux ont incité les participants à ces quatrièmes rencontres internationales sur le classement des contes populaires à donner une existence officielle à leur groupe de travail. Les membres du groupe de recherche ERGON/GRENo (European Research Group on Oral Narratives/ Groupe de recherche européen sur les narrations orales) se donnent en particulier pour but de prolonger la réflexion entreprise dans le cadre de la récente révision de la classification internationale des contes populaires (АтU). Il s'agit, entre autres choses, d'échanger leur points de vue sur les critères de classement, de trouver des corrélations entre les variantes régionales afin d'établir les compléments nécessaires de l'Atu, d'analyser des types concrets de contes à partir de l'information qu'apportent les variantes régionales, etc.

Le groupe se propose de mettre en place des outils informatiques communs permettant l'échange, l'étude et le classement de versions présentes sur une aire donnée afin de les confronter aux répertoires d'autres régions européennes. 